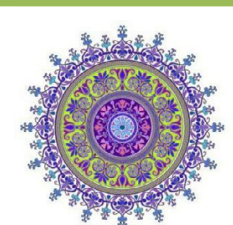

\title{
Correlation between ocular biometric parameters and corneal endothelium in a sample of young Egyptian adults
}

\author{
Mohamed N. Hamza ${ }^{1}$, Maged Maher Roshdy ${ }^{1}$, Mouamen M. Seleet ${ }^{1}$ and Tamer M. El Raggal ${ }^{1}$ \\ ${ }^{I}$ Ophthalmology Department, Ain Shams University Hospitals, Cairo, Egypt
}

\begin{abstract}
Background: To evaluate the normative values of corneal endothelial cell parameters within a group of healthy young Egyptian adults using specular microscopy and to examine any correlations between endothelial parameters and refractive or biometric parameters.

Methods: In this cross-sectional study, specular microscopy was used to study the right eyes of 150 healthy young volunteers and evaluated endothelial cell parameters, including cellular density, hexagonality (HEX), and coefficient of variation $(\mathrm{CV})$ at 15 different points on the back corneal surface, which were later grouped into the central zone and either four quadrants or three annular zones. The same eyes underwent refractive and biometric assessments.

Results: Hundred fifty healthy adults were examined, and the age ranged from 20 to 30 years, with a median of 23 (interquartile range, 21-27) years. The mean \pm standard deviation of central cell density was 2902.7 $\pm 270.7 \mathrm{cells} / \mathrm{mm}^{2}$. The superior paracentral area had the lowest mean density $\left(2895.8 \mathrm{cells} / \mathrm{mm}^{2}\right)$, but the highest mean HEX (67.7\%), while the inferior peripheral area had the highest mean density ( 3100.5 cells/ $\mathrm{mm}^{2}$ ) but the lowest mean HEX (64\%). The difference in cell density among the three annular zones was not statistically significant $(P=0.365)$. However, HEX and CV in the central and paracentral zones differed statistically significantly from those of the peripheral zone $(P<0.001$ and $P=0.014$, respectively). Weak but non-significant correlations were detected between endothelial cell density and all measured refractive and biometric parameters.

Conclusions: The findings of this study provided useful normative biometric and specular data in a specific age group and a specific population, and could be useful in planning intraocular surgery in young Egyptian adults. However, future longitudinal studies with a larger sample could refine more endothelial cell parameter specifications over time.
\end{abstract}

\section{KEYWORDS}

biometry, Egyptian, endothelial cell density, hexagonality, coefficient of variation, specular microscopy, white-to-white

\section{INTRODUCTION}

The corneal endothelium, the most inward of the five corneal layers, comprises metabolically active hexagonal cells that are involved in controlling fluid and metabolite transfer between the aqueous and corneal stromal compartments [1].

Correspondence: Mohamed N. Hamza, Ophthalmology Department, Ain Shams University Hospitals, Ramses St., Cairo, Egypt.

Email: mohamednabil@med.asu.edu.eg. ORCHID iD: https://orcid.org/0000-0002-9737-146X

How to cite this article: Hamza MN, Roshdy MM, Seleet MM, El Raggal TM. Correlation between ocular biometric parameters and corneal endothelium in a sample of young egyptian adults. Med Hypothesis Discov Innov Ophthalmol. 2021 Fall; 10(3): 121-128. https://doi.org/10.51329/mehdiophthal1430 Received: 28 June 2021; Accepted: 21 September 2021

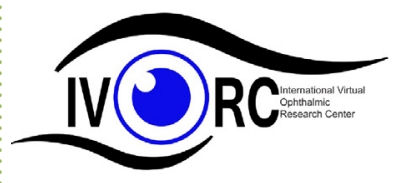

Copyright $(\odot$ Author(s). This is an open-access article distributed under the terms of the Creative Commons Attribution-NonCommercial 4.0 International License (http://creativecommons.org/licenses/by-nc/4.0/) which permits copy and redistribute the material just in noncommercial usages, provided the original work is properly cited. (c) (1) (\$) 
Since endothelial cells are not capable of regeneration through mitotic division, their numbers decline gradually from birth onwards in life by an aging process [2]. This involves a decline in endothelial cell density (ECD), loss of the normal hexagonality of the cells (pleomorphism), and an enlargement of cells adjacent to worn cells (polymegathism) [3]. Many factors have been suggested or proven to influence corneal endothelial parameters. These include physiological factors, such as age, sex, ethnicity, and pathological factors, such as trauma (accidental, surgical, irradiation, or contact lens-induced), long-standing uveitis, and systemic disorders, including diabetes mellitus and chronic renal disorders [4-8].

Different ethnic groups exhibit different endothelial parameters [4, 9-11], which has implications for ophthalmological practice in different parts of the world. This highlights the need for reporting the normative values of corneal endothelial parameters, factoring in other varying ocular parameters on a per-population bases $[11,12]$. Biometric parameters have also been hypothesized to correlate with ECD [13, 14]. In particular, horizontal corneal diameter (white-to-white, WTW) has been reported to correlate significantly with ECD in children [15], but not in the young adult and older age groups [16]. However, most studies have focused on measuring the correlation between biometric parameters and endothelial cell loss postoperatively $[17,18]$, but not in the context of normative population values.

Specular microscopy has been established as a reliable means of examining the corneal endothelium in ophthalmological practice [19]. This non-invasive photographic technique allows visualization and qualitative and quantitative analysis of the endothelial layer [20]. Multiple devices for specular microscopy are commercially available, and all have been demonstrated to provide comparable results. Nevertheless, it is recommended that the same device is used when examining changes in the same eye at different time points [21]. Recently, it has been shown that single central endothelial measurements may constitute a sampling error and may not provide a comprehensive overview of the corneal condition, and that an average of at least 2.9 images is needed to obtain reliable results [22].

In this study, we aimed to assess corneal endothelial parameters comprehensively in a group of healthy young Egyptian adults, using specular microscopy, and to test whether there were any correlations between endothelial parameters and measured refractive and biometric parameters of the same eyes.

\section{METHODS}

We conducted a cross-sectional study that included the right eyes of 150 healthy young Egyptian adults. The study conformed to the tenets of the Helsinki Declaration, and ethics committee approval was obtained from the Ethical Review Committee of the Ain Shams University Faculty of Medicine, Cairo, Egypt. Written informed consent from the volunteers was not required as the data were deidentified, and oral informed consent was deemed sufficient by the ethical committee.

We included healthy subjects between the ages of 20 and 30 years, with healthy eyes based on full ophthalmological evaluation that included thorough medical, surgical, and ocular history taking, refraction (spherical equivalent, SE), best-corrected distance visual acuity (BCDVA) assessment, and slit-lamp examination (Haag-Streit BM 900 slit lamp, Haag-Streit Diagnostics, Bern, Switzerland), including fundus biomicroscopy, as well as intraocular pressure (IOP) measurement by means of an applanation tonometer (KAT T-type, Keeler, PS, USA). Patients were excluded if there was evidence of ocular disease (e.g., corneal scar, endothelial dystrophy, cataract, glaucoma, uveitis), history of wearing contact lenses, prior ocular surgery, ocular trauma, or if the subjects were on any treatment for a chronic systemic disease.

A Nidek CEM 530 specular microscope (Nidek Co., Tokyo, Japan) was used to evaluate the corneal endothelium of all studied eyes, in accordance with the manufacturer's guidelines. Subjects were seated with comfortable head positioning and were asked to focus on the target inside the device. Subjects were asked to perform rapid complete blinking immediately before the measurements were taken, to maintain a smooth tear film over the cornea and to minimize blinking during image acquisition. Substandard scans due to eye movement or blinking during the time of measurement were discarded, and measurements were repeated until images with satisfactory quality was attained. The corneal endothelium was evaluated at 15 points ( 1 central, 8 paracentral, and 6 peripheral points), using the auto-analysis mode. ECD, hexagonality index (HEX), and coefficient of variation $(\mathrm{CV})$ were recorded and analyzed for each of the included points. The values for the ECD, HEX, and $\mathrm{CV}$ were averaged in the four quadrants (upper, lower, nasal, and temporal), and again in three zones (central, paracentral, and peripheral zones).

Biometric parameters were then obtained using an AL-Scan optical biometer (AL-Scan; Nidek Co., Ltd., Tokyo, Japan) on the same day by the same operator. The following parameters were measured: horizontal corneal 
diameter (white-to-white [WTW] distance), central corneal thickness (CCT), average keratometry readings $(\mathrm{Km})$ over a 3.3-mm diameter, axial length $(\mathrm{AL})$, and anterior chamber depth (ACD). Indirect calculation of the corneal surface was carried out using WTW values using the equation: area $=\pi r^{2}$ (where $r=1 / 2 \mathrm{WTW}$, and $\pi=$ 22/7) [23].

Data were collected, revised, coded, and entered into IBM SPSS Statistics for Windows (version 25.0; IBM Corp., Armonk, NY, USA). Normality assumption was tested using the D’Agostino-Pearson test. Data are presented as mean \pm standard deviation $(\mathrm{SD})$ in case of normal distribution and median with interquartile range (IQR) in case of non-normally distributed data. The means were compared using a two-sided $t$-test, while the medians were compared using the Mann-Whitney U test. Correlation was performed using the Pearson test in case of normal data distribution and the Spearman correlation test in case of non-normal data distribution. A one-way analysis of variance (ANOVA) was used to compare three or more means. Post-hoc testing was performed using Tukey's honestly significant difference (HSD) test. The margin of accepted alpha error was set to $5 \%$, and $P$-values $<0.05$ were considered significant.

\section{RESULTS}

Of the 150 healthy adults that were examined, 81 (54\%) were male and 69 (46\%) were female. The age of the subjects ranged from 20 to 30 years, with a median of 23 (interquartile range [IQR], 21-27) years.

Table 1 shows the analysis of the refractive and biometric parameters of the studied samples. The median AL and ACD were $23.85 \mathrm{~mm}$ and $3.60 \mathrm{~mm}$, respectively (IQR, 23.19-24.67, and 3.44-3.80, respectively). The mean \pm SD of CCT was $552.5 \pm 36.5 \mu \mathrm{m}$, and the mean \pm SD of WTW was $12.08 \pm 0.38 \mathrm{~mm}$. The mean \pm SD area of the studied corneas was $114.76 \pm 7.29 \mathrm{~mm}^{2}$.

The average of the major endothelial parameters for each of the measured points on the posterior corneal surface is represented by a heatmap (Figure 1). For the central measurements, the mean \pm SD of the ECD was $2902.7 \pm 270.7$ cells $/ \mathrm{mm}^{2}$, the mean \pm SD of the HEX was $67.62 \% \pm 4.37 \%$, and the median of the CV was 26 (IQR, 24-28). The superior paracentral area had the lowest mean ECD (2895.8 cells $\left./ \mathrm{mm}^{2}\right)$, but the highest mean HEX (67.7\%), while the inferior peripheral area had the highest mean ECD $\left(3100.5 \mathrm{cells} / \mathrm{mm}^{2}\right)$, but the lowest $\operatorname{HEX}(64 \%)$.

Although the ECD was lower in the central zone $\left(2902.7 \pm 270.7\right.$ cells $\left./ \mathrm{mm}^{2}\right)$ than in the paracentral $(2940.2$ $\left.\pm 261.1 \mathrm{cells} / \mathrm{mm}^{2}\right)$ and peripheral $\left(3061.6 \pm 270.3\right.$ cells $\left./ \mathrm{mm}^{2}\right)$ zones, the difference in ECD among the three annular zones was not statistically significant $(P=0.365)$. However, the HEX and CV in the central and paracentral zones were statistically significantly different from those in the peripheral zone $(P<0.001$ and $P=$ 0.014 , respectively). The maximum HEX was detected in the central zone (mean \pm SD, $67.6 \pm 4.4 \%$ ), followed by the paracentral (mean $\pm \mathrm{SD}, 67.2 \pm 3.6 \%$ ) and peripheral (mean $\pm \mathrm{SD}, 65.2 \pm 3.7 \%$ ) zones. The maximum CV was detected in the peripheral zone (mean \pm SD, $27.5 \pm 3.4$ ), followed by the paracentral (mean \pm SD, $26.2 \pm 3.1$ ) and central zones (mean $\pm \mathrm{SD}, 26.0 \pm 3.2$ ) zones.

No statistically significant differences were found between the sexes with regard to median age and SE $(P=$ 0.514 and $P=0.366$, respectively). Males, however, had a statistically significantly higher median AL (24.23 mm versus $23.39 \mathrm{~mm}, P<0.001)$, ACD ( $3.65 \mathrm{~mm}$ versus $3.52 \mathrm{~mm}, P=0.002)$, and mean WTW (12.2 versus $11.94 \mathrm{~mm}, P<0.001)$ than females. On the other hand, females had a statistically significantly higher median

Table 1. Analysis of refractive and biometric data of the 150 healthy adults

\begin{tabular}{|c|c|}
\hline Variable & Value \\
\hline ACD (mm), Median (IQR), (Range) & $3.6(3.44,3.8),(2.61$ to 4.25$)$ \\
\hline AL (mm), Median (IQR), (Range) & $23.85(23.19,24.67),(21.44$ to 29.23$)$ \\
\hline Km (D), Median (IQR), (Range) & $43.06(42.14,44.26),(40.06$ to 47.25$)$ \\
\hline SE (D), Median (IQR), (Range) & $-0.87(-2.72,-0.25),(-15.00$ to 2.87$)$ \\
\hline Area* $^{*}\left(\mathrm{~mm}^{2}\right)$, Mean $\pm \mathrm{SD}$ (Range) & $114.76 \pm 7.29(96.77$ to 134.78$)$ \\
\hline
\end{tabular}




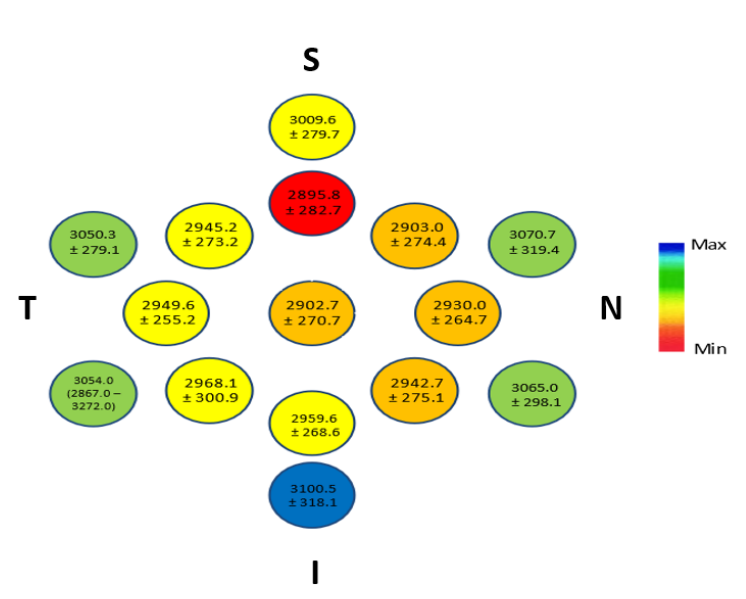

$\mathbf{S}$
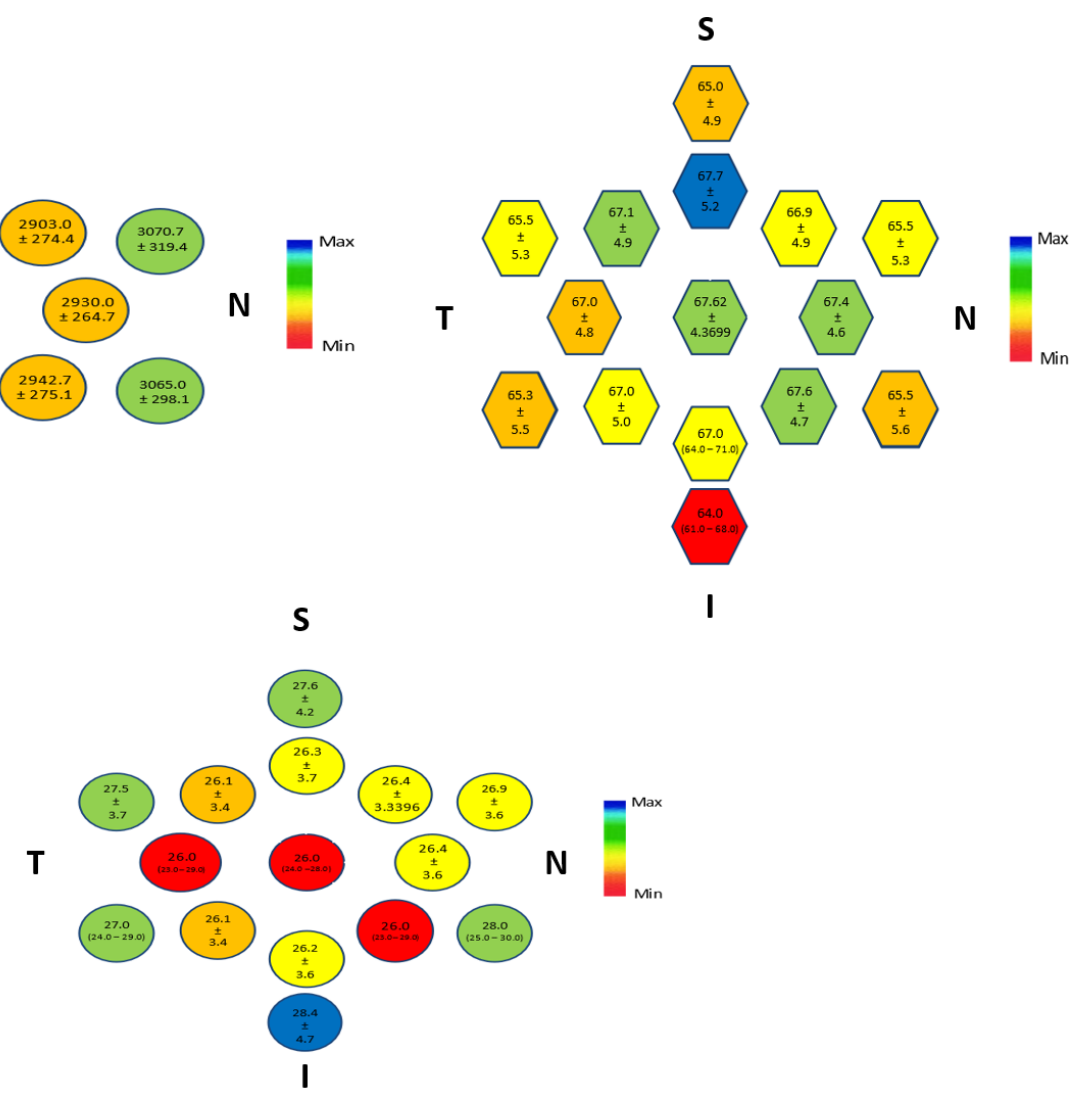

Figure 1. Heatmap representing Top left) endothelial cell density (ECD), Top right) hexagonality (HEX), and Bottom) coefficient of variation (CV) of the measured points. Abbreviations: S, Superior; I, Inferior; N, Nasal; T, Temporal Max, maximum; Min, minimum.

Table 2. Comparison between the sexes regarding endothelial parameters of the 150 healthy adults

\begin{tabular}{|c|c|c|c|}
\hline Variable & Females, $n=69$ & Males, $\mathbf{n}=\mathbf{8 1}$ & $P$-value \\
\hline Central CV, Median (IQR) & $27.0(24.8,28.0)$ & $25.0(23.0,29.0)$ & 0.271 \\
\hline Central ECD $\left(\right.$ cells $\left./ \mathrm{mm}^{2}\right)$, Mean \pm SD & $2901.7 \pm 259.7$ & $2903.5 \pm 281.4$ & 0.692 \\
\hline Central HEX $(\%)$, Mean \pm SD & $67.0 \pm 4.32$ & $68.1 \pm 4.38$ & 0.068 \\
\hline Lower CV, Mean \pm SD & $27.6 \pm 3.2$ & $26.4 \pm 3.3$ & 0.101 \\
\hline Lower ECD $\left(\right.$ cells $\left./ \mathbf{m m}^{2}\right)$, Mean \pm SD & $3022.5 \pm 242.2$ & $3014.6 \pm 280.9$ & 0.774 \\
\hline Lower Hex (\%), Mean \pm SD & $65.0 \pm 3.3$ & $67.0 \pm 3.6$ & $<0.001$ \\
\hline Nasal CV, Median (IQR) & $26.8(25.0,29.4)$ & $26.3(23.8,28.3)$ & 0.159 \\
\hline Nasal ECD $\left(\right.$ cells $\left./ \mathrm{mm}^{2}\right)$, Mean \pm SD & $2974.2 \pm 248.5$ & $2977.0 \pm 281.5$ & 0.619 \\
\hline Nasal HEX (\%), Mean \pm SD & $65.8 \pm 3.3$ & $67.5 \pm 3.5$ & $<0.001$ \\
\hline Temporal CV, Mean \pm SD & $27.2 \pm 2.9$ & $26.1 \pm 3.2$ & 0.081 \\
\hline Temporal ECD $\left(\right.$ cells $\left./ \mathbf{m m}^{2}\right)$, Mean \pm SD & $3008.7 \pm 238.4$ & $2987.7 \pm 265.9$ & 0.982 \\
\hline Temporal HEX $(\%)$, Mean \pm SD & $65.1 \pm 3.2$ & $67.5 \pm 3.4$ & $<0.001$ \\
\hline Upper CV, Mean \pm SD & $27.4 \pm 3.0$ & $26.2 \pm 3.0$ & 0.039 \\
\hline Upper ECD $\left(\right.$ cells $\left./ \mathbf{m m}^{2}\right)$, Mean \pm SD & $2967.6 \pm 247.1$ & $2954.9 \pm 263.7$ & 0.874 \\
\hline Upper HEX (\%), Mean \pm SD & $65.3 \pm 3.2$ & $67.4 \pm 3.7$ & $<0.001$ \\
\hline Paracentral CV, Mean \pm SD & $26.7 \pm 3.1$ & $25.8 \pm 3.0$ & 0.146 \\
\hline Paracentral ECD $\left(\right.$ cells $\left./ \mathbf{m m}^{2}\right)$, Mean \pm SD & $2935.7 \pm 243.1$ & $2944.1 \pm 276.9$ & 0.547 \\
\hline Paracentral HEX (\%), Mean \pm SD & $66.2 \pm 3.3$ & $68.0 \pm 3.6$ & $<0.001$ \\
\hline Peripheral CV, Mean \pm SD & $28.2 \pm 3.0$ & $26.9 \pm 3.5$ & 0.057 \\
\hline Peripheral ECD $\left(\right.$ cells $\left./ \mathrm{mm}^{2}\right)$, Mean \pm SD & $3080.2 \pm 259.4$ & $3045.7 \pm 279.8$ & 0.774 \\
\hline Peripheral HEX (\%), Mean \pm SD & $63.9 \pm 3.3$ & $66.2 \pm 3.7$ & $<0.001$ \\
\hline
\end{tabular}

Abbreviations: IQR, interquartile range; SD, standard deviation; n, number; $\mathrm{mm}^{2}$; square millimeter; \%, percentage; CV, Coefficient of Variation; ECD, Endothelial Cell Density; HEX, Hexagonality index. $P$-value $<0.05$ is shown in bold. Note: Parametric data are reported in terms of mean $\pm S D$ and non-parametric data are reported in terms of median (IQR). 
Km than males (43.57 D versus 42.37 D, $P<0.001$ ). Regarding endothelial parameter differences (Table 2), no statistically significant difference could be detected between the two sexes in terms of ECD and CV in all quadrants and zones (all $P>0.05)$. However, the HEX was significantly lower (all $P<0.001)$ in females than in males in all quadrants and zones, except for the central zone $(P=0.068)$.

Weak correlations, which were not statistically significant, were detected between the central ECD and WTW $(\mathrm{r}=0.013 ; P=0.875), \mathrm{AL}(\mathrm{r}=0.003 ; P=0.968), \mathrm{ACD}(\mathrm{r}=-0.017 ; P=0.834), \mathrm{Km}(\mathrm{r}=-0.111 ; P=0.176)$, and $\mathrm{SE}(\mathrm{r}=-0.005 ; P=0.954)$. The averaged ECD values from all four quadrants and all three annular zones showed correlations when plotted against the aforementioned refractive and biometric values.

\section{DISCUSSION}

In this study, we attempted to analyze endothelial cell parameters in the corneas of healthy young Egyptian adults. The parameters described were within the range of globally reported normative values. Furthermore, we could not detect any significant correlation between the endothelial cell parameters and refractive variables in the study group.

Various studies have shown racial and ethnic differences among different populations [4,14], and it is therefore important to establish normative values to guide clinical decision-making. To the best of our knowledge, there are currently no reports of normal endothelial morphology, values, and their distribution across the cornea for the Egyptian population. Only one study recently published in Egypt [24] has attempted to assess central ECD in a wide range of ages. Our objective was to provide a better understanding of corneal endothelial count and morphological characteristics in different corneal zones and quadrants in healthy young Egyptian adults. This may aid in planning phakic intraocular lens implantation, which is common in this age group.

The mean \pm SD of central ECD in our study was $2902.7 \pm 270.7$ cells $/ \mathrm{mm}^{2}$, which was marginally lower than that reported in a Chinese population (mean \pm SD, $2932 \pm 363 \mathrm{cell} / \mathrm{mm}^{2}$ ) [25], but higher than the normative values reported in a Turkish population (mean \pm SD, $2671 \pm 356$ cells $/ \mathrm{mm}^{2}$ ) [26], Indian population (mean \pm $\mathrm{SD}, 2525 \pm 337$ cells $/ \mathrm{mm}^{2}$ ) [27], and Iranian population (mean $\left.\pm \mathrm{SD}, 1961 \pm 457 \mathrm{cells} / \mathrm{mm}^{2}\right)$ [28]. It is worth noting that these studies examined a wide age range, in contrast to our study, which focused of young adults. A report [29] on a Nigerian population of the same age group (20-30 years) showed a lower mean \pm SD of central $\operatorname{ECD}\left(2860 \pm 227\right.$ cells $\left./ \mathrm{mm}^{2}\right)$.

We also measured the endothelial parameters in different regions (15 specific points) on the corneal back surface and grouped the measurements into quadrants and zones. A similar approach was adopted by Amann et al. [30]. Our results were aligned with their study in finding an increasing ECD from the central to peripheral zones. However, in their study, the superior peripheral region had the highest ECD, as opposed to our study, where the inferior peripheral region had the highest ECD. Furthermore, they found no significant difference in HEX and CV among the three annular zones, while we detected a statistically significant decrease in HEX and an increase in $\mathrm{CV}$ from the central to the peripheral zones. Interestingly, the diameter of the cornea they studied was only $4.7 \mathrm{~mm}$ (versus $7.3 \mathrm{~mm}$ in our investigation). Müller et al. [31] used confocal microscopy and found a higher, albeit statistically non-significant, difference in ECD for the temporal and superior quadrants versus the central area. In our study, the temporal and inferior quadrants had significantly higher ECDs than the central area.

There was no significant difference between females and males regarding ECD and CV in our sample. This finding was supported by previous studies $[4,24,27,29,31,32]$. On the other hand, two studies $[14,33]$ in Southeast Asia (one in Japan and the other in the Philippines) detected a significantly higher ECD in females than in males. However, males had a significantly higher mean HEX than did females in our study sample. This was in contrast to previous work done elsewhere [33], which detected no significant differences between the sexes, and was also in contrast to a previous study on the Egyptian population [24] that found the opposite, with significantly higher HEX in females. The latter study attributed the difference to higher smoking rates in men. We excluded smokers during recruitment, which could explain the discrepancy in the results.

The possible impact of the main ocular refractive and biometric variables on the measurement and analysis of endothelial cells in the normal eyes of the young population has rarely been investigated $[15,16,31]$. It has been hypothesized that corneal ECD measurements can be affected by variations in the corneal diameter and surface area of the endothelium, and that, for more accurate results, the corneal surface area should be factored into the measurement of the ECD [27]. This has been presented as a justification for the significantly lower ECD in the Indian and American population than in the Japanese population [27,34]. However, we could not detect a statistically significant correlation between the WTW and ECD measurements in our study sample. 
A significant negative correlation has been previously established between horizontal WTW and ECD in children [15], but not in young adults [16] or older individuals [31]. This supports the conclusion that the effect may be restricted to infancy and childhood, when the majority of corneal tissue growth is postulated to occur [35-38].

No statistically significant correlation of the ECD with corneal curvature (Km), AL, SE, or ACD was detected. This was in concordance with the findings of Chang et al. [13], who found no significant relationship between corneal curvature and ECD in myopic young adults, and those of Patel et al. [39], who found no correlation between ACD and ECD. Nevertheless, this contradicted the results of Müller et al. [31], who found a significant negative correlation between AL and central ECD in an older population, although they found no significant correlation between SE and ECD. It should be noted that the difference in our studied age groups does not allow for an accurate comparison of these studies.

Our study aimed to determine the connection between biometric variables and the ECD in healthy young adults. It provides valuable baseline biometric and endothelial data for further studies on the impact of intraocular surgery, particularly placement of phakic intraocular lenses, on the corneal endothelium. The latter is an increasingly available option for correcting high refractive errors in the age group we studied here, and is expected to remain in the recipient eyes throughout life. Comparing our data with other published work indicates that the ECD in the Egyptian population is lower than that in the Asian population [25]. The lower occurrence of aphakic bullous keratopathy in Japanese eyes could be related to the higher ECD in these eyes [2, 34, 40, 41]. More studies are necessary to understand whether the reduced endothelial count in Egyptian eyes increases the risk of aphakic bullous keratopathy in this population.

We assessed corneal endothelial parameters comprehensively in a group of healthy young Egyptian adults using specular microscopy. There were limitations to our study, namely the cross-sectional design, small sample size, and narrow age range. Future studies should investigate the effects of biometric variables on the ECD in different age groups and populations, to further our understanding of differences in ECD between individuals, and their implications.

\section{CONCLUSIONS}

The results provide useful normative biometric and specular data in healthy young Egyptian adults and would be useful in planning intraocular surgery in such an age group. Refractive variables should not be relied on as indicators of corneal endothelial status. However, future longitudinal studies with a larger sample with a broader age range could identify more specific characteristics of endothelial cells over time.

\section{ETHICAL DECLERATIONS}

Ethical approval: The study conformed to the tenets of the Helsinki Declaration, and ethics committee approval was obtained from the Ethical Review Committee of the Ain Shams University Faculty of Medicine, Cairo, Egypt. Written informed consent from the volunteers was not required as the data were deidentified, and oral informed consent was deemed sufficient by the ethical committee.

Conflict of interest: None.

FUNDING

None.

ACIRNOWLED GEMENT

None.

\section{REFERENCES}

1. Bourne WM. Corneal Endothelium —Past, Present, and Future. Eye \& Contact Lens: Science \& Clinical Practice. 2010;36(5):3104. doi: 10.1097/ICL.0b013e3181ee1450 pmid: 20724858

2. Bourne WM. Biology of the corneal endothelium in health and disease. Eye. 2003;17(8):912-8. doi: 10.1038/sj.eye.6700559 pmid: 14631396

3. Gambato C, Longhin E, Catania AG, Lazzarini D, Parrozzani R, Midena E. Aging and corneal layers: an in vivo corneal confocal microscopy study. Graefe's Archive for Clinical and Experimental Ophthalmology. 2015;253(2):267-75. doi: 10.1007/s00417014-2812-2 pmid: 25311652 
4. Snellingen T, Rao GN, Shrestha JK, Huq F, Cheng H. Quantitative and Morphological Characteristics of the Human Corneal Endothelium in Relation to Age, Gender, and Ethnicity in Cataract Populations of South Asia. Cornea. 2001;20(1):55-8. doi: 10.1097/00003226-200101000-00011 pmid: 11189005

5. Yeniad B, Corum I, Ozgun C. The effects of blunt trauma and cataract surgery on corneal endothelial cell density. Middle East African Journal of Ophthalmology. 2010;17(4):354-8. doi: 10.4103/0974-9233.71604 pmid: 21180438

6. Schulze S, Bertelmann T, Manojlovic I, Bodanowitz S, Irle S, Sekundo W. Changes in corneal endothelium cell characteristics after cataract surgery with and without use of viscoelastic substances during intraocular lens implantation. Clinical Ophthalmology. 2015; 9:2073-80. doi: 10.2147/OPTH.S90628 pmid: 26609218

7. Zhang K, Zhao L, Zhu C, Nan W, Ding X, Dong Y, et al. The effect of diabetes on corneal endothelium: a meta-analysis. BMC Ophthalmology. 2021;21(1):78. doi: 10.1186/s12886-020-01785-3 pmid: 33568093

8. Toprak I, Fenkci SM, Fidan yaylali G, Martin C, Yaylali V. Effect of microalbuminuria on corneal endothelium in patients with diabetes without retinopathy. Clinical and Experimental Optometry. 2021;103(5):625-9. doi: 10.1111/cxo.12969 pmid: 31625203

9. Duman R, Tok Çevik M, Görkem Çevik S, Duman R, Perente İ. Corneal endothelial cell density in healthy Caucasian population. Saudi Journal of Ophthalmology. 2016;30(4):236-9. doi: 10.1016/j.sjopt.2016.10.003 pmid: 28003782

10. Islam QU, Saeed MK, Mehboob MA. Age related changes in corneal morphological characteristics of healthy Pakistani eyes. Saudi Journal of Ophthalmology. 2017;31(2):86-90. doi: 10.1016/j.sjopt.2017.02.009 pmid: 28559719

11. Tananuvat N, Khumchoo N. Corneal thickness and endothelial morphology in Normal Thai eyes. BMC Ophthalmology. 2020;20(1):167. doi: 10.1186/s12886-020-01385-1 pmid: 32345246

12. Elkitkat RS, Fouad Y, Shams A, Hamza I. Normative Values of Corneal Spherical Aberration, Pupil Size, and Other Key Refractive and Topographic Parameters in a Large Cohort of Egyptian Cataract Surgery Candidates. Clinical Ophthalmology. 2020;Volume 14:4571-7. doi: 10.2147/OPTH.S288738 pmid: 33408459

13. Chang SW, Tsai IL, Hu FR, Lin LL, Shih YF. The cornea in young myopic adults. British Journal of Ophthalmology. 2001;85(8):916-20. doi: 10.1136/bjo.85.8.916 pmid: 11466244

14. Higa A, Sakai H, Sawaguchi S, Iwase A, Tomidokoro A, Amano S, et al. Corneal Endothelial Cell Density and Associated Factors in a Population-Based Study in Japan: The Kumejima Study. American Journal of Ophthalmology. 2010;149(5):794-9. doi: 10.1016/j.ajo.2009.12.029 pmid: 20231011

15. MÜLler A, Doughty MJ. Assessments of Corneal Endothelial Cell Density in Growing Children and Its Relationship to Horizontal Corneal Diameter. Optometry and Vision Science. 2002;79(12):762-70. doi: 10.1097/00006324-200212000-00008 pmid: 12512684

16. Giasson CJ, Gosselin L, Masella A, Forcier P. Does endothelial cell density correlate with corneal diameter in a group of young adults?. Cornea. 2008 Jul;27(6):640-3. doi: 10.1097/01.ico.0000611372.89170.5b pmid: 18580253

17. Walkow T, Anders N, Klebe S. Endothelial cell loss after phacoemulsification: Relation to preoperative and intraoperative parameters. Journal of Cataract and Refractive Surgery. 2000;26(5):727-32. doi: 10.1016/s0886-3350(99)00462-9 pmid: 10831904

18. Reuschel A, Bogatsch H, Oertel N, Wiedemann R. Influence of anterior chamber depth, anterior chamber volume, axial length, and lens density on postoperative endothelial cell loss. Graefe's Archive for Clinical and Experimental Ophthalmology. 2015;253(5):745-52. doi: 10.1007/s00417-015-2934-1 pmid: 25725619

19. Doughty MJ. Non-contact specular microscopy with Topcon instruments to assess central corneal thickness of healthy human eyes - A 20 year review. Contact Lens and Anterior Eye. 2021;44(4):101385. doi: 10.1016/j.clae.2020.11.005 pmid: 33341365

20. Chaurasia S, Vanathi M. Specular microscopy in clinical practice. Indian Journal of Ophthalmology. 2021;69(3):517-524. doi: 10.4103/ijo.IJO_574_20 pmid: 33595465

21. Cakici O, Karadag R, Bayramlar H, Koyun E. Measurements of central corneal thickness and endothelial parameters with three different non-contact specular microscopy devices. International Ophthalmology. 2016;37(1):229-33. doi: 10.1007/s10792-0160264-x pmid: 27221264

22. van den Berg AB, Holzchuh R, Hida RY. Possible Sampling Error in Corneal Specular Microscopy: Can Central Endothelial Data Generated by Specular Microscope Represent the Real Clinical Condition of the Whole Cornea? Cornea. 2020;39(6):779-81. doi: 10.1097/ICO.0000000000002290 pmid: 32073456

23. Stone RA, Lin T, Sugimoto R, Capehart C, Maguire MG, Schmid GF. Corneal surface area: an index of anterior segment growth. Ophthalmic and Physiological Optics. 2001;21(4):286-95. doi: 10.1046/j.1475-1313.2001.00592.x pmid: 11430623

24. Abdellah MM, Ammar HG, Anbar M, Mostafa EM, Farouk MM, Sayed K, et al. Corneal Endothelial Cell Density and Morphology in Healthy Egyptian Eyes. Journal of Ophthalmology. 2019;2019:1-8. doi: 10.1155/2019/6370241 pmid: 30918718

25. Yunliang S, Yuqiang H, Ying-peng L, Ming-zhi Z, Lam DSC, Rao SK. Corneal Endothelial Cell Density and Morphology in Healthy Chinese Eyes. Cornea. 2007;26(2):130-2. doi: 10.1097/ICO.0b013e31802be63e pmid: 17251798

26. Arıcı C, Arslan OS, Dikkaya F. Corneal Endothelial Cell Density and Morphology in Healthy Turkish Eyes. Journal of Ophthalmology. 2014;2014:1-5. doi: 10.1155/2014/852624 pmid: 24683494

27. Rao SK, Sen PR, Fogla R, Gangadharan S, Padmanabhan P, Badrinath SS. Corneal Endothelial Cell Density and Morphology in Normal Indian Eyes. Cornea. 2000;19(6):820-3. doi: 10.1097/00003226-200011000-00012 pmid: 11095057

28. Hashemian MN, Moghimi S, Fard MA, Fallah MR, Mansouri MR. Corneal endothelial cell density and morphology in normal Iranian eyes. BMC Ophthalmology. 2006;6(1):1-5. doi: 10.1186/1471-2415-6-9 pmid: 16519812

29. Ewete T, Alabi A, Ani E. Normal corneal endothelial cell density in Nigerians. Clinical Ophthalmology. 2016. doi: 10.2147/ OPTH.S97070 pmid: 27051271

30. Amann J, Holley GP, Lee S-B, Edelhauser HF. Increased endothelial cell density in the paracentral and peripheral regionsof the human cornea. American Journal of Ophthalmology. 2003;135(5):584-90. doi: 10.1016/s0002-9394(02)02237-7 pmid: 12719063

31. Muller A, Craig JP, Grupcheva CN, McGhee CN. The effects of corneal parameters on the assessment of endothelial cell density in 
the elderly eye. British Journal of Ophthalmology. 2004;88(3):325-30. doi: 10.1136/bjo.2003.019315 pmid: 14977761

32. Al Farhan H, Albaow W, Masoud W. Normal corneal endothelial morphology of healthy Saudi children aged 7-12 years. Journal of the Egyptian Ophthalmological Society. 2014;107(2):63-66. doi: 10.4103/2090-0686.140631

33. Padilla MDB, Sibayan SAB, Gonzales CSA. Corneal Endothelial Cell Density and Morphology in Normal Filipino Eyes. Cornea. 2004;23(2):129-35. doi: 10.1097/00003226-200403000-00005 pmid: 15075881

34. Wörner CH, Olguín A, Ruíz-García JL, Garzón-Jiménez N. Cell Pattern in Adult Human Corneal Endothelium. PLoS ONE. 2011;6(5):e19483. doi: 10.1371/journal.pone.0019483 pmid: 21602935

35. Maripudi S, Byrd J, Qureshi A, Stoleru G, Levin MR, Saeedi OJ, et al. Pediatric Corneal Structural Development During Childhood Characterized by Ultrasound Biomicroscopy. Journal of Pediatric Ophthalmology \& Strabismus. 2020;57(4):238-45. doi: 10.3928/01913913-20200506-01 pmid: 32687208

36. Sehrawat P, Beri S, Garg R, Datta V, Shandil A. Central corneal thickness and corneal diameter in preterm and term newborns and preterm neonates at term. Indian Journal of Ophthalmology. 2019;67(10) :1575-8. doi: 10.4103/ijo.IJO_1988_18 pmid: 31546483

37. Tideman JWL, Polling JR, Jaddoe VWV, Vingerling JR, Klaver CCW. Growth in foetal life, infancy, and early childhood and the association with ocular biometry. Ophthalmic and Physiological Optics. 2019;39(4):245-52. doi: 10.1111/opo.12630 pmid: 31236981

38. Mutti DO, Sinnott LT, Lynn Mitchell G, Jordan LA, Friedman NE, Frane SL, et al. Ocular Component Development during Infancy and Early Childhood. Optometry and Vision Science. 2018;95(11):976-85. doi: 10.1097/OPX.0000000000001296 pmid: 30339640

39. Patel HY, Patel DV, McGhee CNJ. Identifying relationships between tomography-derived corneal thickness, curvature, and diameter and in vivo confocal microscopic assessment of the endothelium in healthy corneas of young adults. Eye. 2008;23(2):270-8. doi: 10.1038/sj.eye.6703091 pmid: 18259207

40. Aketa N, Uchino M, Kawashima M, Uchino Y, Yuki K, Ozawa Y, et al. Myopia, corneal endothelial cell density and morphology in a Japanese population-based cross-sectional study: the JPHC-NEXT Eye Study. Scientific Reports. 2021;11(1):6366. doi: 10.1038/ s41598-021-85617-4 pmid: 33737603

41. Ono T, Mori Y, Nejima R, Iwasaki T, Miyata K. Morphology and cell density of the corneal endothelium of healthy Japanese eyes. Investigative Ophthalmology \& Visual Science. 2021 Jun 21;62(8):802. Link 